\title{
Qual o papel da determinação do aspecto sindrômico através do exame físico para a detecção de cromossomopatia entre pacientes com cardiopatia congênita?
}

\author{
Nogueira, L.T.; dos Santos, C.B.L.; de Morais, C.O.; Yonamine, T.M.; de \\ Mattos, V.F.; Rosa, R.F.M.; \\ Apresentador: Letícia Thaís Nogueira
}

\section{Resumo}

Introdução: As anormalidades cromossômicas são consideradas as principais causas conhecidas de cardiopatia congênita (CC). Elas usualmente se associam a um quadro clínico sindrômico e acometem cerca de 1 em cada 10 pacientes com CC. Nosso objetivo foi verificar se o aspecto sindrômico pode ser utilizado como preditor da presença de anormalidades cromossômicas (ACs) entre portadores de CC. Método: A amostra foi constituída de pacientes com $\mathrm{CC}$ hospitalizados pela primeira vez em uma unidade de tratamento intensiva cardíaca e pediátrica de um hospital de referência do Sul do Brasil. Todos foram submetidos ao exame de cariótipo de alta resolução e de hibridização in situ fluorescente (FISH) para a microdeleção 22q11. Os pacientes foram classificados como sindrômicos ou não por geneticistas clínicos colaboradores do estudo, tomando como base os achados dismórficos observados apenas ao exame físico. Calculou-se a sensibilidade e a especificidade desta abordagem. Resultados: A amostra foi constituída de 198 pacientes, 103 do sexo masculino, idades variando de 1 a 4934 dias $(57 \%$ com $<1$ ano). ACs foram observadas em 32 pacientes (16\%): 23 casos de síndrome de Down, 2 de síndrome de Edwards, 1 de triplo X, 1 de duplicação 17 p, 1 de add(18p) e 4 de microdeleção 22q11. Dos
198 pacientes, 61 (31\%) foram classificados como sindrômicos, sendo que destes, 28 (46\%) apresentavam uma AC. ACs observadas entre indivíduos não sindrômicos (3\%) consistiram do triplo $\mathrm{X}$ e de 3 dos 4 casos de microdeleção 22q11. A sensibilidade desta abordagem foi de $88 \%$ e a especificidade de $80 \%$. Conclusões: A avaliação genética através do exame físico apresenta um importante papel na identificação de portadores de ACs, o que possui implicações sobre o manejo e aconselhamento genético destes pacientes e suas famílias. Chama a atenção que a maior parte dos pacientes com microdeleção 22q11 foi classificada como não sindrômica, o que reflete tanto a sua grande variabilidade fenotípica como a consequente dificuldade na sua identificação.

\section{Referência:}

Nogueira, L.T.; dos Santos, C.B.L.; de Morais, C.O.; Yonamine, T.M.; de Mattos, V.F.; Rosa, R.F.M.;. Qual o papel da determinação do aspecto sindrômico através do exame físico para a detecção de cromossomopatia entre pacientes com cardiopatia congênita?. In: II Congresso Brasileiro de Medicina Hospitalar - II CBMH [= Blucher Medical Proceedings, vol.1, num.5] São Paulo: Editora Blucher, 2014. p.80

DOI 10.5151/medpro-II-cbmh-078 